\title{
Children's Learning, Agency and Power Relations within a Culture of Entitlement with Digital Technology in Schools
}

\author{
Elaine Correa, Francesco Fabbro \\ California State University, Bakersfield, U.S.A. \\ University of Florence, Italy
}

\begin{abstract}
This research study aimed at understanding how teachers and young children use and make sense of digital media in school. Through the use of comparative case studies in Italy and the United States educational practices that employ digital media in schools were examined. In-depth interviews with teachers, and focus groups lead by children comprise the qualitative data collection that relates to children's perceptions and representations of learning, agency and power relations in school.
\end{abstract}

\section{Introduction}

The convergence of technology into daily rituals and practices implies a greater digital presence is evident in the classroom context in general, and particularly flourishing within Early Childhood Education learning spaces. Hence, it should not be unexpected, that technology integration in learning has evolved from a level of policy to required practice within both the American school context of education [8]. Educators are increasingly required to adopt new technologies into their teaching practices. In order to discover and unpack the relationship between digital technology and compulsory education, with the hope of making sense of what happens (and what does not happen) when the digital and the educational come together in the guise of 'school technology' [9], some of the comparative data from a study on digital media and technology in the Early Childhood Education Classrooms in Italy and the USA are examined. The struggle between learning comprehension and effective teaching methods raises numerous interrelated concerns for faculty and students as digital technologies/media become an integral feature of teaching and learning in higher education. Yet, as Selwyn [9] has stated, "despite its prominence, technology use continues to be an area of education that rarely receives sustained critical attention and thought, especially from those people who are most involved and affected by it".

\section{An International Comparative Study}

In a comparative research study commissioned through the University of Verona, (Verona, Italy), and conducted by researchers from the Department of Education and the Department of Philosophy, Education and Psychology, the meaning and associated value of digital technologies within primary schools was explored. With the use of case studies, small focus group discussions lead by the children themselves, and in-depth interviews of teachers by the three researchers on the team, the meaning of digital technologies in the context of schools in Italy and the United States was examined. Two case studies were completed, one in Rome, and the other in Verona, Italy. As a comparative point of reference, a case study was also conducted in an urban, downtown city school in Buffalo, New York, over the 2015-2016 academic year. A pilot study was conducted in Verona, Italy with all three researchers participating in the initial interviews with teachers from two rural school districts. From the preliminary findings, the researchers developed the protocol and interview questions to be used for the Italian context and translated into English for the American context.

\section{Methodology-Grounded and Student- led}

The voices of the different participants in the classroom (students and teachers) were the conceptualized starting point for the research study. The social patterns and structure of digital learning practices grounded how the researchers identified concepts and coded recurring themes, patterns and issues that resonated in the data. From the studentled focus groups, and in-depth interviews with teachers, the intersection of children's perceptions of learning, agency and power emerged. The in-depth interviews with teachers aligned with recurring contemporary issues in education that were mirrored in pedagogical practices and perceived expectations related to the use of digital technologies in teaching. In total, 120 students participated in the study, with 6 teachers providing in-depth interviews as well as several different opportunities for the researchers to observe classroom teaching practices over the school year.

The research study results reflected some rather interesting trends that highlighted the struggle between learning comprehension and effective teaching methods for young children. In our 
understanding of how teachers and students use and make sense of different educational and teaching practices with digital media in their specific contexts, we privileged a 'socio-cultural' approach to the study of teaching practices with digital media [2], 1990; [3], [6], [13]. Upon closer examination, the case studies approach [11] revealed an unanticipated pattern that extended across geographical regions and cultural differences. It was the research team's expectation that with two distinctly different countries and teaching/learning environments that the study would yield significantly distinct approaches and outcomes with how technology integration would be viewed or embraced in the context of the primary school classroom.

Additionally, it was assumed that many of the differences would emerge from the embedded sociocultural differences between Italian and American society. However, the intersecting issues that emerged in this comparative case study directly responded to the learned meanings of digital technologies in school in contrast to the socially accepted understanding of teaching and learning within the primary school level. What was interesting to note was that from time to time, the researchers from both countries indicated concern about how the students were responding in the focus group discussions that were led by the teacher versus the independently led conversations that evolved naturally amongst the children themselves. There was a sense and/or feeling of being played when students were playing with educationally driven technologies in the classroom. What was further surprising was how this same pattern also emerged in the data collection results across each case study.

One of the significant outcomes from the interplay of students playing with technology and the researchers experiences of being played by students, subsequently emerged in the data results. The researchers began to question whether the young participants were effectively playing a system of education to their advantage, as they became experts in understanding how traditional values of learning are aligned to technology integration in schools. Within this paper, some of these dynamics will be discussed to further explore how teaching in a culture of technology entitlement in learning is heavily influenced by the way technology integration may be positioned in schools in the American and Italian context. A duality of meaning is discussed in how digital technology integration in primary schools is supported and may thereby influence not only what occurs in the classroom, but also what does not materialize in practice.

\section{Recurring Patterns and Themes}

Five central categories were identified within the research data collected from the in-depth interviews with teachers in the American and Italian case studies. Some of these recurring themes, patterns and issues that emerged include power, politics, control, and conflict as well as matters of empowerment, equality, social justice, and participatory democracy. Several of these categories are repeated in the justification by teachers as to why they integrate specific forms of technology into their teaching practices. Specifically, in the American case, the implication of State Standards [7] and accountability concerns, were the most compelling reason for responding to increased usage of technology in teaching. The pressure to demonstrate competency and skills without diluting the value of student's educational experiences were interconnected to the concern about how education was perceived as a product with associated cost value and aligned to the demand for more interactive learning. Teachers expressed that training was often insufficient, yet assumed, as in the case study in the United States, to be somewhat automatically embraced by the teachers to complete on their own time. Here the societal influences as expressed through State proposed policy changes [1] imposed immediate expectations and modifications to curricula without regard to teacher competencies or skills.

Teachers identified significant frustration with the way technology was imposed upon them as a solution to improving student learning in both the Italian and American case studies. Specifically, in the American case study, the expectations of the State, such as the move towards Common Core created greater upheaval for teachers to remain current and on task with the new demands that had been imposed upon them by new State policies. In an effort to address these discrepancies in educational performance, the State imposed the regulation of schools with standardized testing enforcing greater restrictions on teachers to exercise control over "how they teach" and mandated that teachers focus on adherence to standardized curriculum that must be covered over the course of the school year. As a result, the standardizing of the curriculum has meant that greater emphasis is placed on test scores and overall student performance in defining the effectiveness of teachers in schools. A reversing of how we measure learning is evidenced with the emergence of a type of 'report card' for teachers, where their effectiveness is based on how well their students perform on State exams. Essentially, teachers were expected to produce student success by adhering rigidly to the prescribe curriculum, incorporating technology enhanced drill activities, with the intent of increasing test scores over the course of the year. This form of accountability that is correlated directly to the effectiveness of teachers based on student scores, did not take into consideration differences in the student population, 
or individualized learner needs that each teacher serves in the classroom. The Italian teachers identified similar concerns with the attention that is placed on PISA rankings, particularly in comparison of Italy within the European context. The unintended outcome of policies and rankings has significantly impacted how teachers respond to curricular demands. In the American context, teachers place considerable attention on how the desired outcomes will ensure their longevity in the field.

While the debate rages onward as to the efficaciousness of State control over classroom teaching practices, the impact of the State exercising greater control has been expressed as problematic in both formal and informal ways by teachers across school districts. Teachers may unintentionally view these forms of control as a reason to become more insular and competitive with their colleagues as opposed to working collaboratively in partnership with their peers. Current research supports the use of Communities of Practice as a means of engaging learning through the active and purposeful exchange and dialogue between teachers, and practitioners across classrooms. Student perceptions of how their teachers work, or do not work together, was also mirrored in the way technology was used by students to compete against each other rather than work collaboratively in groups. For example, individual learning time with a State-initiated Program that was initially intended to provide test scores for each child throughout the school year with a computer-based program, morphed into a competition between students who had different classroom teachers. Students believed that their teacher was better than the other teachers because their test scores were higher. What was intended to generate data on student comprehension as a required assignment that all students were expected to complete became a competition to measure teacher effectiveness.

The expectation that technology would serve as the ultimate equalizer in terms of redressing inequities between students in the classroom was another issue that was viewed as deeply problematic within the American context. Students were often unable to follow the instructions that were embedded in technology enhanced programs that were used for accountability checks in meeting State standards. For example, an individual sixteen-digit code was required as the identification marker for each student. This code had to be inserted within the designated time allocated, prior to the start of the program for each individual student's responses to be coded and aligned with the State's scoring rubric. The child's progress was dependent on quickly typing in the code and hitting the return button to activate the program. Teachers were needed to type in the code for each student because of the limited time provided for students in the lower grades to be able to quickly type in their identification numbers.
These imposed curriculum changes can be viewed as a direct hit against professional teachers in the United States, given that little, or limited consultation with teachers took place prior to the imposition of these changes. Furthermore, with limited research to support the efficacy of these changes, it was anticipated that teachers would be less than willing to embrace changes that are not evidence-based or supported by teaching practices. As a result of this tension, there remains underlying resistance to the types of curriculum changes that have been imposed and whether these changes will actually produce the intended results to warrant the complete overhaul that has had to occur to align with new State policies. In the Italian context, the pressures to improve remain constant with greater emphasis placed on the effectiveness of teachers from rural areas compared to teachers working within suburban schools. These tensions reinforce the competitiveness that teachers recognize as an unhealthy consequence of increased pressures to meet and integrate increased digital content in their classes.

Some of the major themes and responses from the teachers across the different locations and countries resonated with very similar comments related to the use of technology in teaching. Technology as a part of society was a general theme that respondents identified, both in terms of how integrated technology had become in the lives of people from a macro level to the impact of technology in schools at a micro level. Technology was used for everything, and therefore recognized as an integral component of everyday life for both adults and students. Teachers commented specifically about the societal influences of technology in relation to educational policies and new procedures. Many teachers felt that they were either not trained sufficiently to implement different forms of technology into their classroom teaching, or they were very reluctant to consider different teaching practices that required technology because they did not feel they had mastered the program or tool. In addition to the policy changes around technology in schools, teachers identified concern about how technology would be expected to impact student learning. This was another theme that teachers identified in face-to-face interviews in both Italy and the United States.

One of the recurring areas of concern that was voiced by teachers was the modifications to teaching that were driven by technology and reinforced through new Standards and expectations within the curriculum. While the teachers were readily cognizant of the need for equipping children with greater technological skills and abilities, they often expressed concerns about their own knowledge base and competencies or lack thereof with technology. Several comments from teachers focused on the lack 
of appropriate training or rudimentary knowledge of the new programs and forms of technology that they were expected to integrate seamlessly into their teaching practices. For some teachers, the opportunity to learn more about these technologies was seen as an essential step that was often overlooked or missed by school boards in their haste to move forward with programs and tools which the teachers had little or no training using within the classroom.

Most teachers identified a colleague in their school who had some knowledge or interest in technology, and thus quickly became "the IT guru or go to person" to provide the support they needed. However, the majority of the teachers were not satisfied with the ways they were presented new curriculum to cover that required comprehension of different technology tools and the lack of training or support that they received for integrating technology into their teaching. These types of concerns were considered by the researchers in understanding why some teachers were more hesitant and very reluctant to provide access to their classrooms for our observations. Additionally, with the pressures that teachers identified experiencing with greater measures of accountability and the heavy focus on State Standards, the fear of some teachers was related to how the findings from this study would be used. It was noted by the researchers that the teachers who were more inclined to participate in this study were seen by their colleagues as early adopters who either had experience with technology or liked trying new things in the classroom. These individuals were often not the most senior teaching faculty members, and usually were identified by their Principals as the more innovative teachers in the school.

The use of technology was not perceived as an unreasonable request by the teachers. However, the way that technology became a part of the teaching requirements and the insufficient support and training were the fundamental issues that teachers indicated could have been handled differently. The ways in which technology was presented was another concern, particularly in how technology was aligned as a tool for accountability and the maintenance of standards. Here the expectation that students should have greater access to technology tools shifted from a discussion of learning more about the array of tools available for student learning to the demands of entitlement about how technology will benefit the standardizing of the curriculum but also provide ways to check and micromanage teachers pedagogical practices. In this format, technology became a tool of oppression for some teachers who felt that they were being judged by standards that were next to impossible to achieve. The hidden agenda was clear to many teachers in the American context. Technology was to be used to measure teacher effectiveness in student test scores, but also in terms of how quickly and successfully teachers were able to cover curricular content. Many teachers worried that the current model of accountability as aligned with standards would induce a teach to the test mentality amongst teachers in order to demonstrate effectiveness in teaching. With the growing demands placed on teachers, the culture of entitlement that continued to be promoted by School districts was to do what was needed to keep the parents happy, the principal satisfied, and the superintendents pleased by the positive scores earned with the use of these drill and skill computer programs. Whether students were enjoying this learning experience was not paramount. All that seemed to be of value in the minds of the teachers was the need to demonstrate success both in high test scores and competency using the various technologies (smart boards, diagnostic programs for skill training, and interactive educational games).

The statements from teachers about the means by which student learning was increasingly becoming commercialized as a product for sale, was interconnected with how little value was placed on learning for knowledge acquisition. Many of the teachers expressed concern about the way that teaching was less about assisting students and more reflective of a business model of product and services. In this sense, several teachers felt that they had become subject to the corporate mentality of providing value in terms of the commodity of learning for the price tag (taxes) that was paid for children to attend schools. With less of a focus on whether students are able to apply their learning, the model of education as a product for consumption was a central theme in how teachers expressed demoralization and indifference in how their understanding of being a teacher had radically changed. Comments such as "I am not paid enough" or "teachers are not in this profession for the pay" were clearly articulated in responses from teachers about the loss of direction that occurs when education becomes a product for sale.

Teachers did surprisingly express considerable hope that once the perceived bumps with technology were ironed out, that more progress could be made with the integration of technology in teaching. Specifically, teachers identified that using technology to support rather than be the central theme of their teaching would ensure greater alignment with student learning and current pedagogies of teaching. Here the teachers were anticipating that technology would serve as a tool in support of current teaching practices. In this way, accountability to State Standards would not be dependent on computer generated programs designed to demonstrate student learning by the number of questions they were able to answer correctly, but rather that the full scope of student needs would be 
evidenced in how students could apply their learning to a specific task. Teachers were adamant that the "skill and drill exercises that students performed on an individual computer were of no real difference to the paper and pencil drill and skill tests of the past".

Figure 1: Major themes/responses alignment

\begin{tabular}{|l|l|}
\hline Theme/Pattern/Issue & Response \\
\hline Technology in Society & $\begin{array}{l}\text { Societal Influences on } \\
\text { Educational Policies }\end{array}$ \\
\hline $\begin{array}{l}\text { Technology in } \\
\text { Learning }\end{array}$ & $\begin{array}{l}\text { Modifications to Teaching } \\
\text { in Technology Driven } \\
\text { Learning Environment }\end{array}$ \\
\hline Culture of Entitlement & $\begin{array}{l}\text { Expectations and Demands } \\
- \text { Accountability and } \\
\text { Standards }\end{array}$ \\
\hline $\begin{array}{l}\text { Education as A } \\
\text { Product }\end{array}$ & $\begin{array}{l}\text { Investment based on } \\
\text { Price/Cost and anticipated } \\
\text { Value }\end{array}$ \\
\hline $\begin{array}{l}\text { Interactive Learning vs } \\
\text { Edutainment }\end{array}$ & $\begin{array}{l}\text { Competency and Skills for } \\
\text { both 'Content Expertise' } \\
\text { and 'Digital Literacy }\end{array}$ \\
\hline
\end{tabular}

\section{Normalizing Practices}

Regular visits to the school in both the American and Italian context, were intended to establish a normal presence of the researcher in the classroom with the students. In the American context, the current policy for access to the students and teachers in the school requires a formal meeting with the Principal to discuss the purpose of the research study, a discussion about the number of visits and the time or duration that would be needed had to be identified before signed approval was completed. In the American case, the teacher indicated interest in providing the researcher with a real experience of student engagement with technology integrated learning, so the regular visits to the classroom were extended to ensure that students would be comfortable with a foreign presence in the classroom. The teacher did acknowledge that students had become aware of the various patterns of inspectors who visited the classroom for different assessment requirements throughout the week, for the School District and State. The students were familiar with these people entering the classroom sometimes weekly or bi-weekly. The teacher felt that a similar format of visits by the researcher would help to normalize the researcher's presence in the classroom. As mentioned, the classroom teacher felt that regular visits by the researcher would provide a more realistic picture of the technology integration used in the classroom as well as properly reflect the student's comfort in utilizing technology.

Over the course of three months, the researcher made bi-weekly visits to the classroom. It became quickly apparent that the students began to feel comfortable with the researcher's presence and forget that there was another person in the classroom. The level of comfort extended to moments where some of the students would ask the researcher questions about the classroom assignments or relay information about something that happened to them during the week. While the teacher identified these exchanges with the researcher as "evidence" of student comfort with the researcher's presence in the classroom, there were moments where this sense of comfort was questionable. For example, students often chanted formal greetings to visitors who entered the room as encouraged by the teacher. Students knew that when the Principal or other classroom teachers came to the door, they were expected to greet these individuals appropriately. In the third month of visits one of the students asked "why the researcher didn't have to participate in the greeting if she was coming to the class to learn?" The teacher explained that the researcher didn't know all the teachers in the school. The student expressed that "if the researcher didn't participate, then how could she learn?" This exchange revealed the understanding by the student that all classroom participants were expected to actively engage in the activities. The fact that someone was not participating was not a normal learning practice. At the same time, the student was questioning why the practices for learning were different for the researcher. It was apparent that this difference was not normal and that the researcher's presence also was not normal despite the assumption that over time, the researcher's presence in the classroom would not be noticed.

The assumption that the teacher made about children's awareness of the different actors in the classroom is important here, as in the same way, the teacher assumes that the children are not aware of the educational script that they must participate in to be successful in school. On several occasions, students were asked by the teacher if they "liked the interactive lesson" where technology was integrated into the lesson. Similar to their recited greetings that the students used to acknowledge other authority figures in the classroom, the students would respond with a scripted "yes" in unison. However, when examining the drawings and associated texts of students about their experiences with technology, the focus of technology was solely in terms of the representation of large screens. There were no direct comments about the technology in the written text. Rather, the written texts reflect the pleasure of movement in the classroom, and not a focus on the actual technology used or the value of the technology for learning. Similar findings were evident in the Italian cases, where students even identified the use of technology as simply a lecture on the smartboard. Students quickly acknowledged that using 
technology to teach did not automatically translate into enjoyment. Technology as a tool, like any other tool in the classroom does not change the teaching method if the teacher uses the technology in the same way as a worksheet distributed to the class. The only difference for students was that the technology was used to project the class assignment, instead of distributed individual hardcopies to students for their responses.
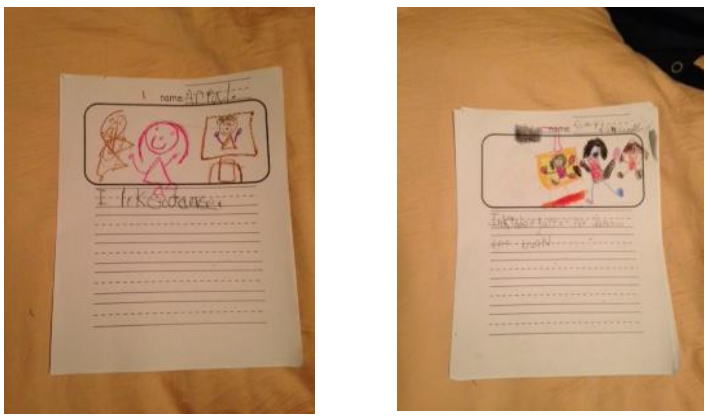

Figure 2: "I like to dance" responses to the use of Counting with Mario - Technology Video Clip

Students were also easily distracted with specific activities were the technology replaced the paper and pen drills with the computer and mouse. The substitution of technology for these skill and drill exercises were quickly defined as "boring" and "no fun" loosely translated as not enjoyable or entertaining. The lack of flashy, quick paced movement of images was seen as exercises that were identified as "hard" and "too long". It is important to note, that these exercises were less than 10 minutes of instruction. The engaged learning moments seemed to emerge more with activities where students were timed to complete the task in teams using competition amongst groups as a motivator. The technology use in these activities centered more on practical aspects of technology such as large print of questions projected for everyone to see on the smartboard. From the simple exercise of students taking responsibility for their own attendance in class by directly touching the smartboard screen and dragging their names from the list onto the attendance sheet with the use of the pointer pen, to the more elaborate group activities where students were required to read along with a predesigned text and answer questions on the computer, the opportunities where children physically engaged in their learning were identified as the most enjoyable aspects of learning with technology.

\section{Edutainment-Learning Should be Fun}

There were many drawings where the children indicated the desire that technology be used not solely for learning but rather as edutainment. These drawings tended to feature the technology in the background with the focus on student movement and pleasure in the foreground. Several students wrote comments that endorsed the importance of learning as fun. These comments ranged from "I like to dance" to "In kindergarten, we dance on the board". This comment is a direct reference to the American case when the teacher used a dancing video (dance with me) as a bonus at the end of the lesson. In addition to the opportunity for students to dance with the video instructing "What does the fox do?" video clip, the children also indicated that they like to sing and physically move around. The images of children in the classroom singing also reflect movement of the participants in the drawings. "I like when the teacher plays the Mario song". In the Italian case studies, a similar theme was evident in how the teacher was positioned as providing boring information, even when using a smart board and technology to relay information to students. However, when the teachers provided break times with interactive video clips and movies, students were quick to identify these learning situations as most enjoyable and desired.

\section{Children's perceptions and representations of learning, agency and power relations}

In focus group discussions of four to five children in the classroom, the researcher was provided an opportunity to "listen in" on student discussions. These discussions were moderated by the children themselves. The researcher was provided opportunities to actively listen and learn without directing the students with any specific questions. The children exchanged comments with their peers about their own drawings and experiences with technology in the classroom. Specifically, their comments were directed to the digital media that was used in the prior classroom activity. As per the instruction of the teacher, the students were asked to sit in groups and draw what they liked from the previous learning activity. Each child received a piece of paper that was divided with two distinct sections: a blank space on the top half of the page, followed by a series of lines for written text on the bottom half of the page. This format was used for students to combine visual images with text reflecting a storybook approach to document their learning.

As the children were sitting in groups, the teacher encouraged them to use this opportunity to speak with their peers about what they were drawing and why. This format or approach provided ample opportunity for the researcher to learn how children felt about playing with technology and their perceptions of learning, agency and power relations 
within the classroom. The children identified how they preferred using the video games that they were permitted to play during the recess break, or when they had completed the computer exercise tests. The children recognized that their teacher would be unable to quickly reboot the computer when glitches occurred with the technology connections. The children repeated the word "reboot" often when they thought there was a connection issue. When students were asked what the word reboot meant, they were unable to explain the word. However, they were cognizant of the agency and power they could exercise by uttering this word at the hint of a technology issue. In small ways, children had learned the code for creating more time away from drill and skill exercises using the smart board when their teacher fiddled with improving the computer connection. Although teachers may not realize the ways children interrupt and internalize their learning with the use of technology, the perceptions of children's representation of learning reflects their recognition of the differences between playing with technology (outside of school) versus learning with technology (inside school).

\section{Conclusion}

Teachers are quite aware of the gains that can be achieved with the integration of new technologies and interactive learning strategies that are aligned with video games and social media. However, while teachers attempt to create alliances with integrating components of these games as a means to manage student learning, they also must juggle the reality of limited resources. Although teachers may wish to use elaborative sophisticated options to engage students, they are constantly reminded of the societal influences that impact educational policies with technology integration, where modifications to teaching are imposed with very limited consultation with educators. Furthermore, the expectations and demands that contribute to the pressures for accountability and standards in education only exacerbate the culture of entitlement to technology that enforces models of success based on competency and skills of teachers as both content experts with exceptional digital literacy. The investment costs associated with education reflects the representation of education as a product that should include some immediate return value. For children, these issues are embedded and intersect the limitations of learning with technology that they receive within schools. Children recognize the limitations of exercising their agency and power in relation to the ways they are taught, as well as what they are taught with technology versus what forms of learning (games, augmented reality) are not permitted within school as legitimate forms of learning engagement.

\section{References}

[1] Adams Becker, S., Cummins, M., Davis, A., Freeman, A., Hall Geisinger, C., and Ananthanarayanan, V. (2017). NMC Horizon Report: 2016 higher Education Edition. Austin, Texas: New Media Consortium. Retrieved from http://ww.nmc.org/publications/nmc-horizon-report-2017higher-education-edition

[2] Apple and Jungck, (1990). "You don't have to be a teacher to teach this unit": Teaching, technology, and gender in the classroom, American Educational Research Journal, 27, 2, pp. 227-251.

[3] Buckingham, D. (2007) Beyond Technology. Children's learning in the age of digital culture. Cambridge: Polity.

[4] European Commission (2018). Communication from the Commission to the European Parliament, The Council, The European Economic and Social Committee and the Committee of the Regions. Digital Education Action Plan, Brussels. https://eur-lex.europa.eu/legal-content/EN/ TXT/PDF/?uri=CELEX:52018DC0022\&from=EN

[5] Fabbro, F., Agosti, A., Correa, E. (2017). Pratiche digitali nella scuola primaria:il bambino è protagonista? (Digital practices in primary school: is the pupil protagonist?) Form@ re Open Journal per la formazione in rete Tecnologie nella scuola e apprendimento. Criticità $e$ potenzialità, Vol 17, No. 1, (pp. 68-81). DOI: http://dx.doi.org/10.13128/formare-20195.

[6] Giroux, H., (2001). Theory and Resistance in Education. London: Bergin \& Garvey.

[7] New York State Education Department (2016). The New York State Prekindergarten Foundation for the Common Core. Retrieved from http://www.nysed.gov/curriculum-instruction

[8] Office of Education Technology, (2016). National Education Technology Plan. Department of Education, United States of America. From http://tech.ed.gov/netp/.

[9] Selwyn, N. (2011) Education and Technology. Key Issues and Debates. London-New York: Continuum International Publishing Group.

[10] Selwyn, N. (2013) Education in a digital world: global perspectives on technology and education. London: Routledge.

[11] Yin R., K. (1994) Case Study Research: Design and Methods, Third edition, Thousand Oaks-London-New Delhi: Sage. 